\title{
Application of Health-Improving Technologies in Tb-Infected Preschool Children
}

\author{
Victoria Aleksandrovna Martynova ${ }^{1}$ \\ ${ }^{1}$ Kazan Federal University, Elabuga, Moscow, Russia \\ Correspondence: Victoria Aleksandrovna Martynova, Kazan Federal University, Elabuga, Kazanskaya str. 89, \\ 423600 Moscow, Russia. E-mail: viktoria2580@mail.ru
}

Received: August 15, 2014

doi:10.5539/mas.v8n6p306
Accepted: September 18, $2014 \quad$ Online Published: November 19, 2014

URL: http://dx.doi.org/10.5539/mas.v8n6p306

\begin{abstract}
In this article we review an impact of the experimental program on physical health of TB-infected preschool children. The purpose of this study is to improve physical health of TB-infected preschool children. We revealed theoretical and experimental grounds of health-improving technologies for TB-infected preschool children. The program has been designed given the prevalence of disease and has a multicomponent structure. This program has differentiated content and it's designed for children from the two age groups. The program has been approved and all the results are presented in this article. On review the dynamics of morphofunctional features and morbidity during an experiment we improved the level of all the studied parameters.
\end{abstract}

Keywords: physical education, health, TB-infected children, preschool age

\section{Introduction}

Public health is a key indicator of socio-economic development of the country and one of the main criteria of life quality. The processes of public health formation quite objectively reflect the social living environment and characterize the environment of a particular region to some extent (Diberovska, M. and D. Dacevski, 2005; Maher, D. and M. Raviglione, 2005; D. Hamilton a. J.AL Nabulsi, 2000).

Nowadays deteriorating of the health of children and adolescents is the problem of particular concern. Their total quantity in the general population has been decreased by 4.2 million and is now equal to 35 million. About $75 \%$ of preschool children have serious deviations in health. Among primary school children healthy ones make up to $10-12 \%$, and among older - only $5 \%$. Chronic diseases are diagnosed in more than $50 \%$ of children of various age (Federal State Statistics Service, 2014).

According to the Federal State Statistics Service 26,579.6 thousand children have been diagnosed with respiratory lung diseases in 2012 as a result of the primary analysis in children versus $22,952.2$ thousand cases in 1995.

In Russia in 2012 there were 97.5 thousand registered patients diagnosed with active tuberculosis versus 85.0 thousand cases in 1995 (Federal State Statistics Service, 2014).

Analysis of scientific and methodical literature and pedagogical practices revealed that both sanatorium treatment and prevention activities used in existing kindergartens are carried out exclusively by physicians, while educational activities - by teachers. It's important that these activities were designed for healthy children (Izarovskaya, I.V., 2004).

\section{Methodology of the Study}

Experimental activity was carried out on the basis of municipal preschool institutions. The study enrolled 112 TB-infected preschool children in the age of 5-7 years with abnormal results of Mantoux test. All the subjects underwent a thorough medical examination and a course of treatment in tuberculosis clinic of Naberezhnye Chelny. After the course of treatment they were referred to rehabilitation in pre-school educational institution (PEI) designed especially for their health improving. TB-infected preschool children were divided into two groups - the test group (TG) and the control group (CG) - both included 56 subjects. The study also involved 60 children of the same age from the basic medical health group, including 30 boys.

Solving problems of the research was carried out through a number of methods, including: analysis and 
synthesis of scientific and methodical literature; analysis of medical and educational records; the method of anthropometry; the method of indices; pedagogical observation; pedagogical experiment; methods of mathematical statistics.

Anthropometry was conducted in accordance with the guidelines of the Russian system for monitoring of physical development and physical fitness of children, adolescents and youth. Anthropometric measurements were carried out to assess the level of physical development of the test subjects according to the standard procedure and standard tools. In particular the following parameters were assessed: body length (cm), body weight $(\mathrm{kg})$, vital capacity $(\mathrm{ml})$, breathing delay at the height of inspiration (s), heart rate (HR), blood pressure (BP), Romberg test, step-test.

In anthropometrics we widely use indexes in order to assess physical development, detection of the age and other changes in the growing organism. Evaluation indexes are derived by comparing different anthropometric characteristics.

We used the following indices in our study:

1. Double product - Robinson $=(\mathrm{HR} * \mathrm{BP}$ (syst) $) / 100$ (standard units)

2. Skibinski index $=(\mathrm{VC}(\mathrm{ml}) \mathrm{x}$ breathing delay at the height of inspiration $(\mathrm{s})) / \mathrm{HR}(\mathrm{bpm})$

3. Vital Index (VI) = VC/body weight in kilograms; where VI - vital index, $\mathrm{ml} / \mathrm{kg}$; VC - vital capacity, ml;

Physical performance of TB-infected children was determined by the modified step test.

All the data obtained were subjected to statistical analysis involving the following criteria:

- $\quad$ check of normality of distribution by Shapiro - Wilkie criterion (criterion W);

- judgment of equal variances - by F-Fisher test;

- $\quad$ in order to test the hypothesis on the difference between the two average values we applied two-sample Student's t-test for independent samples;

- $\quad$ in case samples didn't have a normal distribution the comparison was made by nonparametric Mann and Whitney test for independent samples.

Statistical analysis has been done on the computer using the statistical package SPSS, Statgraphics Plus for Windows and Data Analysis in Microsoft Excel.

\section{Results of the Study}

Objective of the study: to develop and substantiate physical education program of TB-infected children of preschool age as well as pedagogical conditions of its realization in terms of pre-school educational institution designed especially for children's health improving.

We have proposed a program of physical education of TB-infected children of preschool age called "Zdoroveyka", which has the following structure: passport of the program, explanatory note, structure and content of the program, forms of physical training organization, methodological features of the program, pedagogical conditions for effective implementation of the program (Martynova, V.A., 2013.).

Purpose of the program - to increase the level of physical health of TB-infected preschool children (we have evaluated physical health of preschool children in terms of physical development, the level of physical training and morbidity).

Objectives of the program:

- health-improving (improving of physical development and physical training reducing an incidence of acute respiratory diseases, immunity strengthening and improving);

- educational (formation and improvement of vital motor skills, development of psycho-physical qualities; formation of basic knowledge about types of the tourism, natural phenomena, orienteering, initial environmental knowledge);

- educative (training of independent physical activities; education discipline, self-organization skills, honesty, courage, responsiveness, good attitude towards comrades; promote mental processes; comprehensive harmonious development of the child: intellectual, moral, aesthetic and labor).

- corrective (correction and improvement of respiratory function; correction of physical development and physical training; correction and normalization of psycho-emotional state, formation of non-specific resistance of TB-infected preschool children to harmful environmental factors). 
The development of physical education program of TB-infected preschool children is based on the following pedagogical principles:

$>$ principle of individually differentiated approach that takes into account characteristics of the children groups in the framework of the program: age, health status, the level of physical activity and physical training, adaptability to preschool conditions;

$>$ principle of consistency, meaning the possibility of high performance of the program at action coordination of all subjects of educational process: teachers, phthisiologists, medical personnel, psychologists, administrators, parents and children of preschool age themselves;

principle of complexity, which involves a combination of treatments carried out in the preschool institutions (herbal tea, physiotherapy, massage, therapeutic physical culture), and content of physical education programs of TB-infected children of preschool age (Zotova, F.R. and V.A. Martynova, 2012.)

The program consists of two main blocks: basic and variable one. Scope of the program is designed for three classes per week, two of which cover the realization of base program and one covers the realization of a variable block. It should be noted that the experimental program is designed for children of two age groups: 5-6 years and 6-7 years.

Base unit of the program is based on the program "Education and training in kindergarten" (Vasilieva M.A., Gerbova V.V., Komarova T.S., 2004) (section "Physical Education") and contributes to the achievement of educational, recreational and educative objectives.

Variadic block involves solving of correctional tasks of the program. In this block we have picked up those means that influence favorably the respiratory system of the children according to the authors Shchetinin M.N., Pegrum Juliet, Lewis K.L.

The variable part included such means of physical education as: travel exercises, health-improving outdoor activities, breathing exercises, yoga elements, psycho-gymnastics by Chistyakova M.I., and acupressure by Umanskaya A.A.

The developed program of physical education was implemented in the following forms of classes organization: physical education, morning hygienic gymnastics, pauses for physical training, sports leisure, athletic festivals, independent motor activity.

Physical education classes are the main form of physical education in TB-infected preschool children. The following types of physical education classes were conducted as a part of our program:

- physical education classes, according to the program "Education and training in kindergarten" (2 times per week);

- classes of therapeutic physical culture;

- physical education classes as part of variable block of the program (once a week).

- $\quad$ independent motor activity;

- $\quad$ sports and recreational activities in the day mode: gymnastic leisure, gymnastic holidays, health day.

Various forms of touring physical training was proposed by T.P. Zavyalova as part of a pilot program of physical education of TB-infected children

- natural history walks, exploration walks, quest walks, training classes, subject-role classes, gaming classes, competitions were conducted throughout the whole year. Motor tasks became more and more complex, both for individual members of the tourist group, and for the whole group. At the same time equipment in the area of kindergarten and the surrounding area with its natural and social objects is widely used (Zavyalova, T.P., 2000)

- Morning hygienic gymnastics included general developmental, breathing exercises, acupressure by A.A. Umanskaya, gymnastics complexes with music. In senior and preparatory groups gymnastics was used for 15 minutes.

- Pauses for physical training were conducted in the classroom for writing, drawing, speech development. These activities required focusing on the traditional method, 2-3 exercises in the form of a game lasting for 2-3 minutes.

- Self motor activity of children in warm seasons. Mobile games for the development of physical qualities, i.e. game with running, jumping, throwing, etc. were conducted. 
- Gymnastic leisure and sport holidays were conducted as forms of active recreation.

- Gymnastic leisure: 1 time per month for 45-50 minutes in the senior and preparatory groups of children. Games and races, travel, tourism walking with an emphasis on the development of physical qualities were used.

- Gymnastic holidays - twice during the year. Parents and the entire staff of preschool educational institution were involved in these activities.

To enhance the impact of correctional health tools we used an individual work with preschool children. We also used a homework, the implementation of which was controlled by parents.

Methodological features of the program are the following:

1. Monitoring the adequacy of the chosen physical load for an individual program, as well as physical activity at home; we have modified criteria of adequacy of the chosen load for capabilities of preschool children proposed by S.V. Khrushchev.

2. Complex combination of specific and nonspecific means of physical training is the methodological feature of the developed physical education program for TB-infected children of preschool age.

3. Given that a TB-infected preschool child comes to compensating preschool for 6-12 months of rehabilitation, the selection of various forms of physical education and dosing of physical loads was performed taking into account the stage of his stay. With this regard, we distinguish three stages of rehabilitation: adaptation (3-4 weeks), gently-coaching (16-17 weeks), coaching (20 weeks) (Khrushchev, S. V., 2006).

Pedagogical conditions that ensure the effectiveness of the above-noted programs for the recovery of TB-infected preschool children by means of physical training are:

1. Active position of the family in matters of rehabilitation of children of preschool age, cooperation of preschool institution and family in sports and recreation activities.

2. Participation of the entire teaching staff, health professionals and administration in improving work that can be achieved by the formation of special knowledge and skills for the recreation activities. Their belief in the importance and effectiveness of such work, moral and material incentives for their activities in this direction are also very important factors.

3. Individually-typological targeting and matching of health-improving program to possibilities and needs of preschool children, dosing of physical activities during the implementation of the program with regard to the age, severity of intoxication, period of being in preschool institution, the level of physical readiness and motor activity, health and mental development of children.

4. Creating special psycho-pedagogical and everyday comfort in preschool institution for the rapid adaptation of preschool children with respiratory diseases and their rapid inclusion in rehabilitation activities (Martynova V.A., Zotova F.R., 2012).

The study of changes in physical development during the period of the experiment showed that the following parameters have considerably changed in girls at the age of 5-6 years from the test group: Skibinsky index - in the beginning of the experiment, this indicator was equal to $78.75 \pm 20.97$ conditional units, and after the experiment $-157.24 \pm 18.70$ (an increase was equal to $99.66 \%$ ), step test $-41.0 \pm 4.48$ conditional units in the beginning of the research and $56.22 \pm 5.47$ at the end of the research (an increase was equal to $37.12 \%$ ), vital capacity $842.85 \pm 97.7 \mathrm{ml}$ in the beginning of the experiment and $1075.0 \pm 89.33 \mathrm{ml}$ after the experiment (an increase was equal to $27.54 \%$ ), life index $47.57 \pm 4.61 \mathrm{ml} / \mathrm{kg}$ and in the end $-56.60 \pm 8.26 \mathrm{ml} / \mathrm{kg}$ (an increase was equal to $18.98 \%$ ), and Romberg test showed $22.45 \pm 7.59 \mathrm{~s}$ and $32.75 \pm 9.74 \mathrm{~s}$ respectively (an increase was equal to $45.87 \%$ ). In the test group of girls at the age of 5-6 years an increase in the same parameters for the same period was equal to $47.66 \%$ Skibinsky index ( $74.96 \pm 20.85$ and $110.69 \pm 25.42$ conditional units), step test $6.39 \%$ (41.14 \pm 43 . и $77 \pm 4.57$ conditional units), vital capacity $15.48 \%$ ( $835 \pm 16.9$ и $964.28 \pm 79.4 \mathrm{ml}$ ), life index $9.77 \%$ (48.28 \pm 6.51 and $5.0 \pm 7.27 \mathrm{ml} / \mathrm{kg}$, and Romberg test $26.43 \%$ (22.43 \pm 5.11 and $28.36 \pm 5.57)$ respectively.

In the group of boys in the age 5-6 years the following parameters have considerably changed: an increase in Skibinsky index was equal to $109.28 \%$, step test was increased by $38.76 \%$, vital capacity increased by $34.80 \%$, life index increased by $26.63 \%$, and Romberg test increased by $30.17 \%$. In the test group of boys in the age 5-6 years an increase in the same parameters was equal to $55.43 \%, 11.92 \%, 14.37 \%, 13.01 \%, 11.92 \%$ respectively. It is to be noted that though the groups had not validly differ from each other by the indexes of physical development, by the end of the experiment, girls of the EG were validly ahead of their herd mates from the CG 
$(\mathrm{p}<0.05)$. The data is shown in Figure 1.
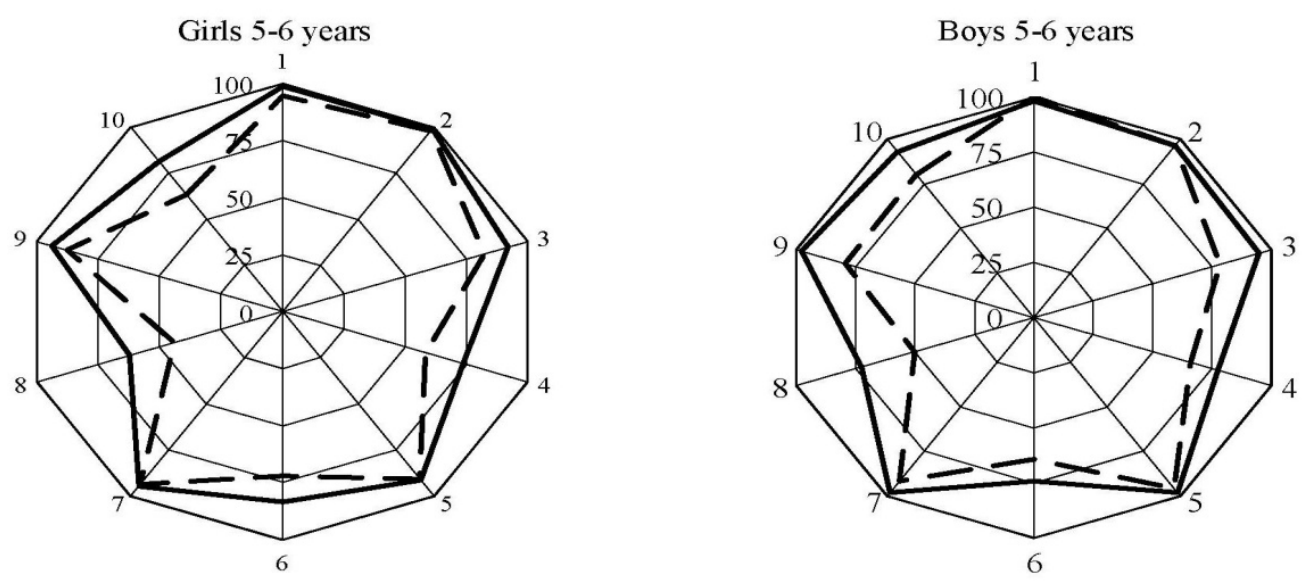

Group of healthy children, ------ test group; --- --- control group

Note: 1 - body weight, 2 - body length, 3 - vital capacity, 4 - Stange test, 5 - HR 6 - Romberg test 7 - Robinson index, 8 - Skibinsky index, 9 - life index, 10 - step test

Figure 1. Levels of physical development of preschool children in the age of 5-6 years after the experiment (\%)

Figure 2. presents the physical development of TB-infected preschool children after the experiment. To assess an impact of the physical education program, we have examined the dynamics of sick days during the educational experiment as well as the physical development of the children.

During 10 months of the experiment children in the control group missed out 1,122 days due to the disease.

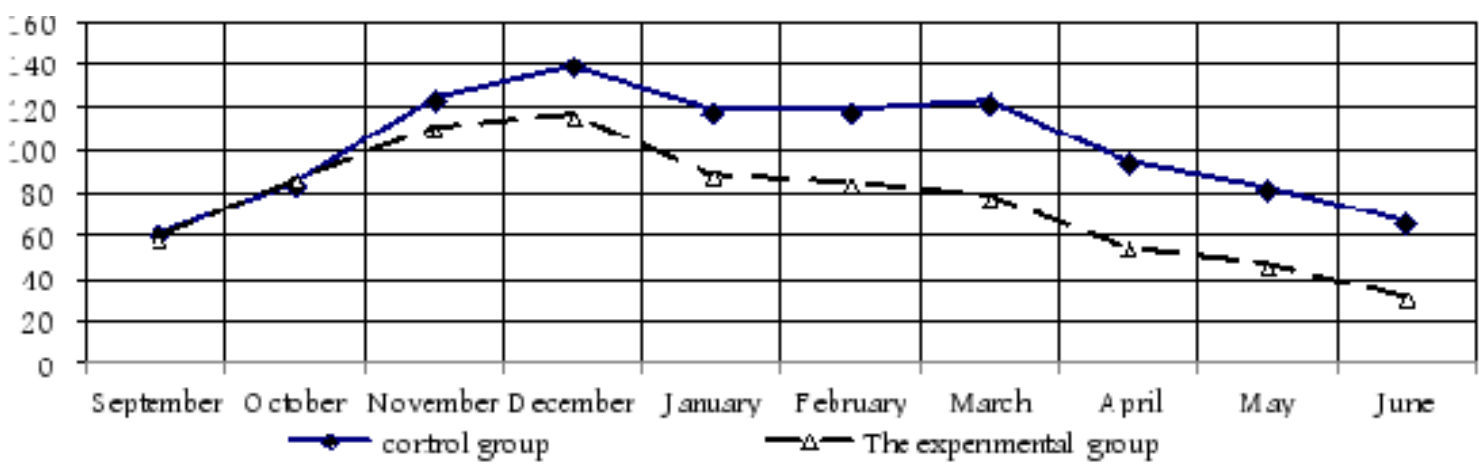

Figure 2. The number of sick days of children in the age of 6-7 years during the experiment period

In the experimental group, this parameter was 952 days. At the same time there were 40 sick days per one child in the control group, while in the test group this parameter was 32 days (Figure 2).

Considerable decrease in the number of days of disease in the experimental group per one child by the end of the experiment strongly evidences the efficiency of the impact of the program means on the health of the trainees.

However, the analysis of the incidence of diseases with pre-school children during the experiment allowed revealing that significant increase in incidence is observed in November, December, and March. The diseases are determined, to our opinion, by the seasonal climatic peculiarities: during these months, considerable fluctuation of ambient temperature is observed in Russia.

\section{Discussion}

The analysis of scientific and methodical literature revealed the following:

1. Tuberculosis germs don't always cause the disease entering the human body. An increased risks of TB 
development include: children from the families of TB patients not vaccinated with BCG due to contraindications, healthy children with conversion of tubercular tests, children without vaccination scar, children of early preschool age, children with chronic nonspecific diseases of lungs and upper respiratory tract. Children of an early age are particularly susceptible for this disease. The main features of TB-infection according to the authors (D. Hamilton a. J.AL Nabulsi., 2000; Ed.by Mauro Bendinelli a. Herman Friedman., 1988.; World health organization, 1988; Antonio Pio, Pierre Chaulet, 2000.) are the following: retardation in growth and especially in weight; lack of the appetite; long, narrow, flat chest; hyperadenosis and induration of lymph glands, nervous irritability, sensitivity, rapid fatigue, headaches; poor appetite, low-grade fever (up to 37-37.4 degrees); positive TB reactions; reduced amount of hemoglobin and red blood cells.

2. In Russia, various rehabilitation centers sanatorium-type kindergartens, sanatorium-type schools don't provide solutions for appropriate medical, health and other problems. In existing sanatorium-type kindergartens treatment and prevention work are carried out exclusively by physicians. Educational work is carried out by teachers according to the programs designed for healthy children. At the same time physical culture and the natural factor in the recovery of this contingent are not fully used. Often physical development and the level of physical fitness of these children are not taken into account. (Aliyev, M. N., 1978).

Thus, we have revealed the following conflicts:

- between high wellness, corrective and developmental potential of physical culture on the one hand, and relative unreadiness of physical education programs in TB-infected preschool children in compensating preschool educational institution - on the other hand;

- between the necessity for introduction of the new health and fitness programs in rehabilitation process of TB-infected preschool children (such programs should consider physical development and physical fitness of this group of children) and the lack of theoretical and methodological foundations of its elaboration in relation to this contingent.

\section{Conclusion}

It should be noted that by the end of the experiment the difference between the test group and the control group increases dramatically. At the beginning of the experiment children had approximately the same level of physical development and physical training. By the end of the experiment due to the implementation of the experimental program, we achieved a considerable increase in many parameters in the test group of preschool children that were significantly higher than those parameters for girls and boys from the control group.

However, it should be noted that the level of physical development of TB-infected child after the conducted study is considerably below the level of a healthy child.

\section{References}

Aliyev, M. N. (1978). Experimental justification of a technique of classes in physical culture for pupils of sanatorium boarding schools of a tubercular profile: abstract of the thesis for the title of candidate of pedagogical sciences /M N. Aliyev. - M, p. 23.

Clinical imaging in non-pulmonary tuberculosis/Francis E. McGuinness; With contributions by D. Hamilton a. J.AL Nabulsi. - Berlin: Springer, Cop. 2000. p.192.

Diberovska, M., \& Dacevski, D. (2005). Tuberculosis in children risk factors. European Respiratory Journal, 26(Suppl. 40), 2705.

Federal State Statistics Service. (2014). Retrieved from April 4, 2014, http://www.gks.ru/wps/wcm/connect/rosstat_main/rosstat/ru/statistics/population/healthcare/\#

Hesova, E. Rodicovske zdruzenie/E. Hesova // Predskolska Vjchova.-2002/03 - Roc. 57, № 4. - S. 24-28.

Izarovskaya, I. V. (2004). Characteristics of the processes in children at the age of 5-6 years in Chelyabinsk on applying the complex of health-strengthening technologies, thesis of Candidate of Biological Sciences, South Ural State University, Chelyabinsk, pp. 163.

Khrushchev, S. V. (2006). Physical culture of children with diseases of respiratory organs/Page V. Khrushchev, O. I. Simonova. - M.: Academy, p. 304.

Lewis, K. L. (2004). Yoga for the special child(tm): Effects on physical and social development in preschool children. M. S. University of Nevada, Reno, pp. 152. 
Maher, D., \& Raviglione, M. (2005). Global epidemiology of tuberculosis. Clinics in Chest Medicine, 26, 167-169. http://dx.doi.org/10.1016/j.ccm.2005.02.009

Martynova, V. A., \& Zotova, F. R. (2012). M29 The content and organization of physical education of TB-infected preschool children: monograph / VA. Martynova, F. R. Zotova. - Yelabuga: Kazan Federal University, P. 320.

Martynova, V. A. (2013). Correctional and health-improving program of physical education for TB-infected preschool children. Bulletin of Chelyabinsk State University, 34, 56-59.

Martynova, V. A. (2013). Rehabilitation of TB-infected children of preschool age by means of physical training. Digest of Scientific Papers SWorld, 52(3), 83-88.

Mycobacterium tuberculosis Interactions with the immune system Ed.by Mauro Bendinelli a. Herman Friedman. - New-York; London : Plenum press, Cop.1988. p426.

Pegrum, J. (2004). Children's yoga. Fun with a twist. London: CICO books, p128.

Schetinin, M. N. (2009). Breathing exercises by Strelnikova make a miracle. Moscow: ACC-Center, p106.

Summer, Y. U.A. of a way of identification and outcomes of a tubercular infection at children: aвтореф. уеw. ... edging. medical sciences/Yu.A. Summer. - SPb. 2002.p. 18.

Tuberculosis control as an integral part of primary health care. - Geneva: World health organization, 1988. p47.

Tuberculosis handbook/Writing comm.: Antonio Pio, Pierre Chaulet.-Repr. - Geneva : World health organization. Global tuberculosis progr., 2000. - 222 s.

Yanchenko, M. S. (2000). Tuberkulez at children and teenagers: the management for doctors/M of S. Yanchenko. - L.: Medicine, p287.

Zavyalova, T. P. (2000). Metodika of use of means of tourism in physical education of children of 6-7 years in preschool educational institution: yew. ... edging. пед. sciences/T.P. Zavyalova. - Omsk, p172.

Zotova, F. R., \& Martynova, V. A. (2012). Physical education of preschool children in preschool health-improving institutions. Physical Culture: Upbringing, Education and Training, 3, 11-15.

\section{Copyrights}

Copyright for this article is retained by the author(s), with first publication rights granted to the journal.

This is an open-access article distributed under the terms and conditions of the Creative Commons Attribution license (http://creativecommons.org/licenses/by/3.0/). 